\title{
Determining the volatile composition of the ancient mantle through the analysis of Archean aged fibrous diamonds
}

\author{
MICHAEL BROADLEY ${ }^{1}$, DAVID BYRNE ${ }^{1}$, MAYA G \\ KOPYLOVA $^{2}$, EMILIE THOMASSOT ${ }^{3}$, MATTHIEU \\ ALMAYRAC $^{4}$ AND BERNARD MARTY ${ }^{5}$ \\ ${ }^{1}$ Centre de Recherches Pétrographiques et Géochimiques \\ ${ }^{2}$ University of British Columbia \\ ${ }^{3}$ Université de Lorraine, CNRS, CRPG \\ ${ }^{4}$ CRPG Université de Lorraine \\ ${ }^{5}$ Université de Lorraine \\ Presenting Author: michaelwbroadley@gmail.com
}

The study of noble gases in mantle-derived basalts has been central to our understanding of the degassing history of different mantle reservoirs and the formation of the atmosphere [1]. However, the ubiquitous presence of shallow-air contamination in these samples often results in the original mantle derived signature being obscured. Furthermore, alteration of basaltic glass samples soon after eruption ensures that only the youngest freshest glass samples are able to provide insights in to the volatile composition of the mantle [2]. These limitations coupled with the fact that the record of oceanic crust only extends back around 200 million years means our knowledge of the past mantle composition and degassing state is unknown.

Fluid inclusions trapped during diamond formation can provide pristine information on the nature of ancient mantle volatile sources due to the robustness of the diamond host [3]. We analysed the noble gas composition of fibrous diamonds from the Wawa in the Superior craton in Canada. These diamonds were recovered from a metaconglomerate unit that formed at $2.7 \mathrm{Ga}$, and therefore provide a rare opportunity to study a "proven" Archean mantle fluid source [4]. The noble gas ( $\mathrm{He}, \mathrm{Ne}$ and $\mathrm{Ar}$ ) isotope systematics of the diamonds show a remarkable similarity to the modern upper mantle, suggesting that the lithospheric mantle was extensively degassed early in the Earth's history. Furthermore, the identification of a modern day mantle noble gas signature in the Archean aged diamonds suggests that the lithospheric mantle reservoir has remained relatively isolated since the time of the diamonds formation. These new data provide important constraints for mantle convection models, indicating that mantle processing / degassing was significantly more efficient in the Archean [5] and has not significantly altered the lithospheric mantle composition since.

[1] Parai et al., (2012) EPSL 359, 227-239.

[2] Broadley et al., (2017) G3 18(7), 2413-2428.

[3] Broadley et al., (2018) GPL.

[4] Smith et al., (2012) Geology 40(12), 1071-1074.

[5] Marty et al., (2019) Nature 575(7783), 485-488. 